\title{
Utilizing Ambient Stable Isotope Distributions for Pumping Test Interpretation in a Glacial Outwash Aquifer in Minnesota
}
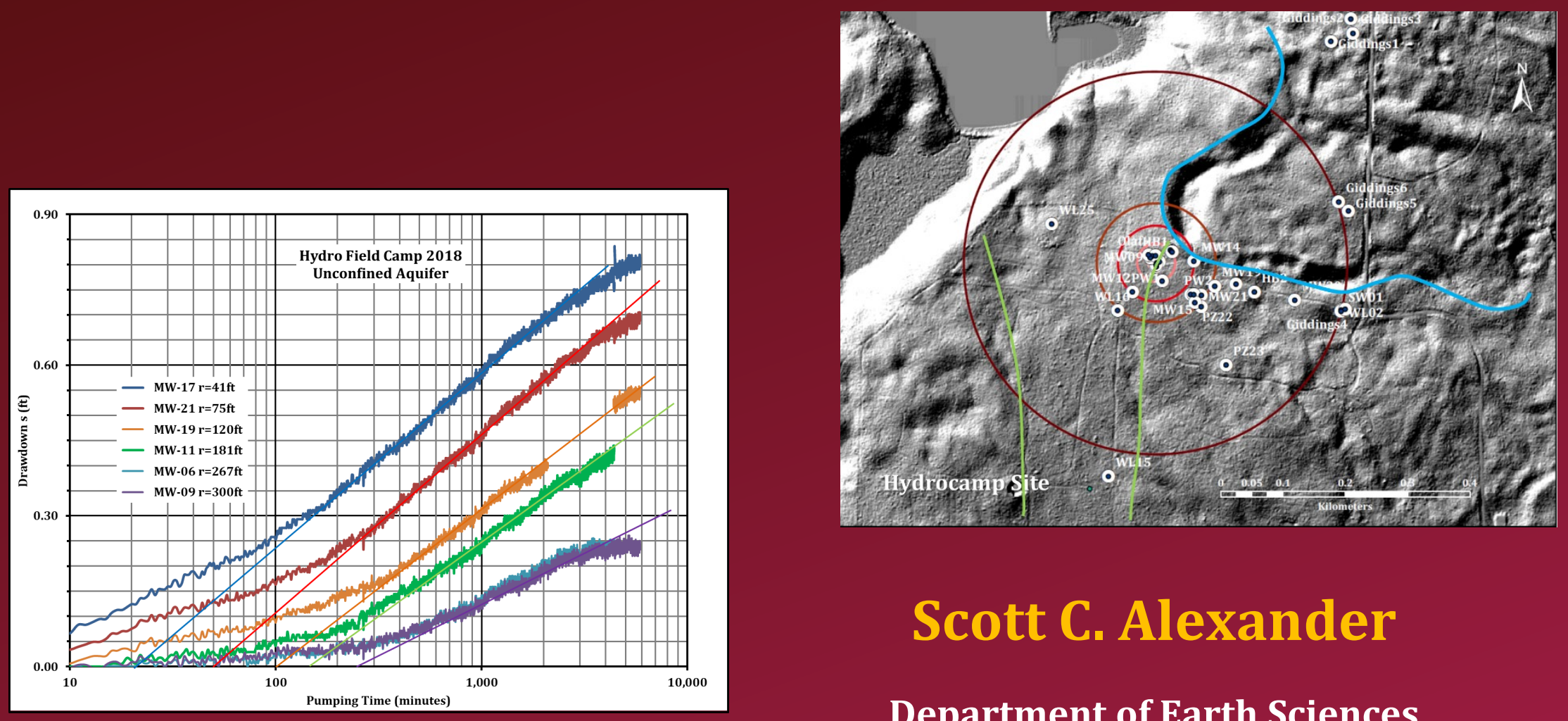

\section{Scott C. Alexander}

Department of Earth Sciences University of Minneapolis Minneapolis, MN 


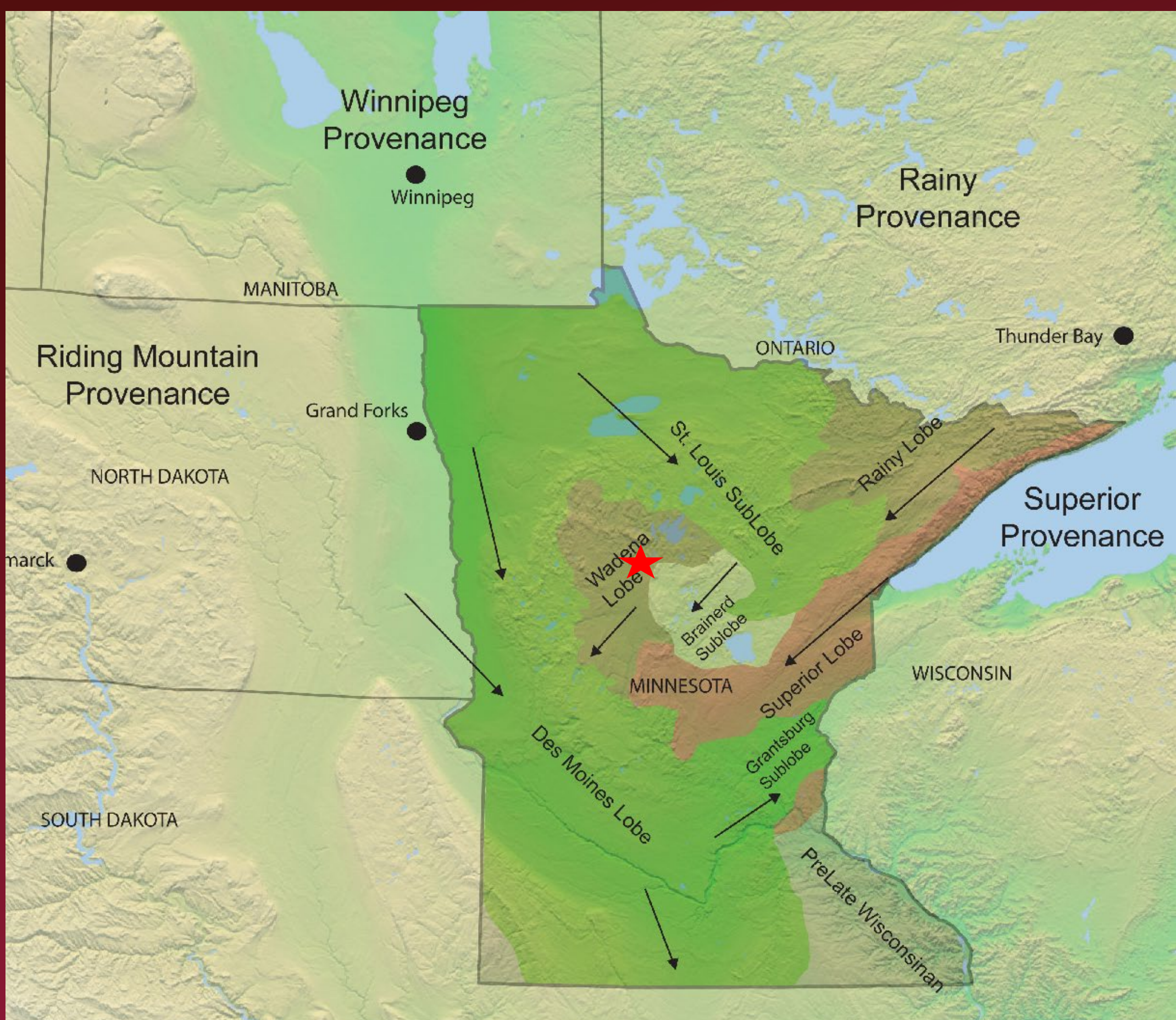




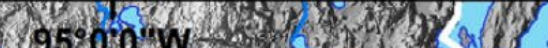

Nild $96^{\circ} 0^{\prime} 0^{\prime \prime} \mathrm{W}$
Wild Ris

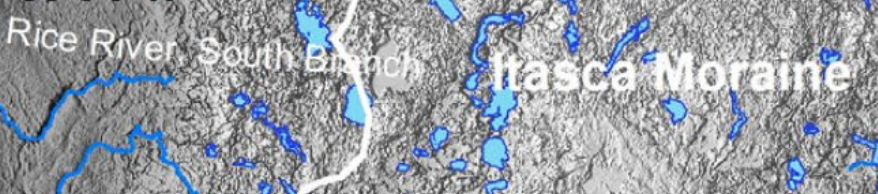

(1)

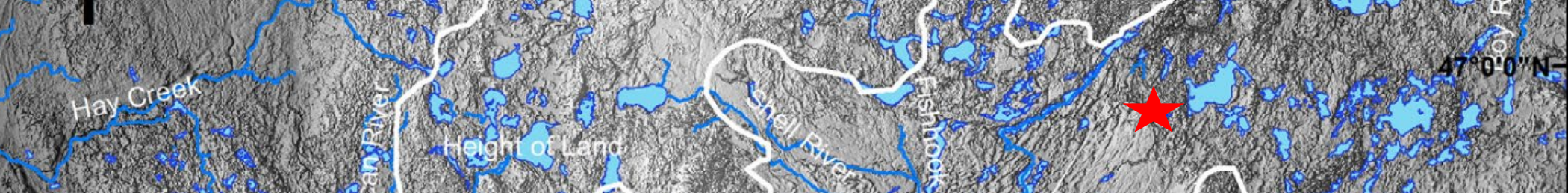

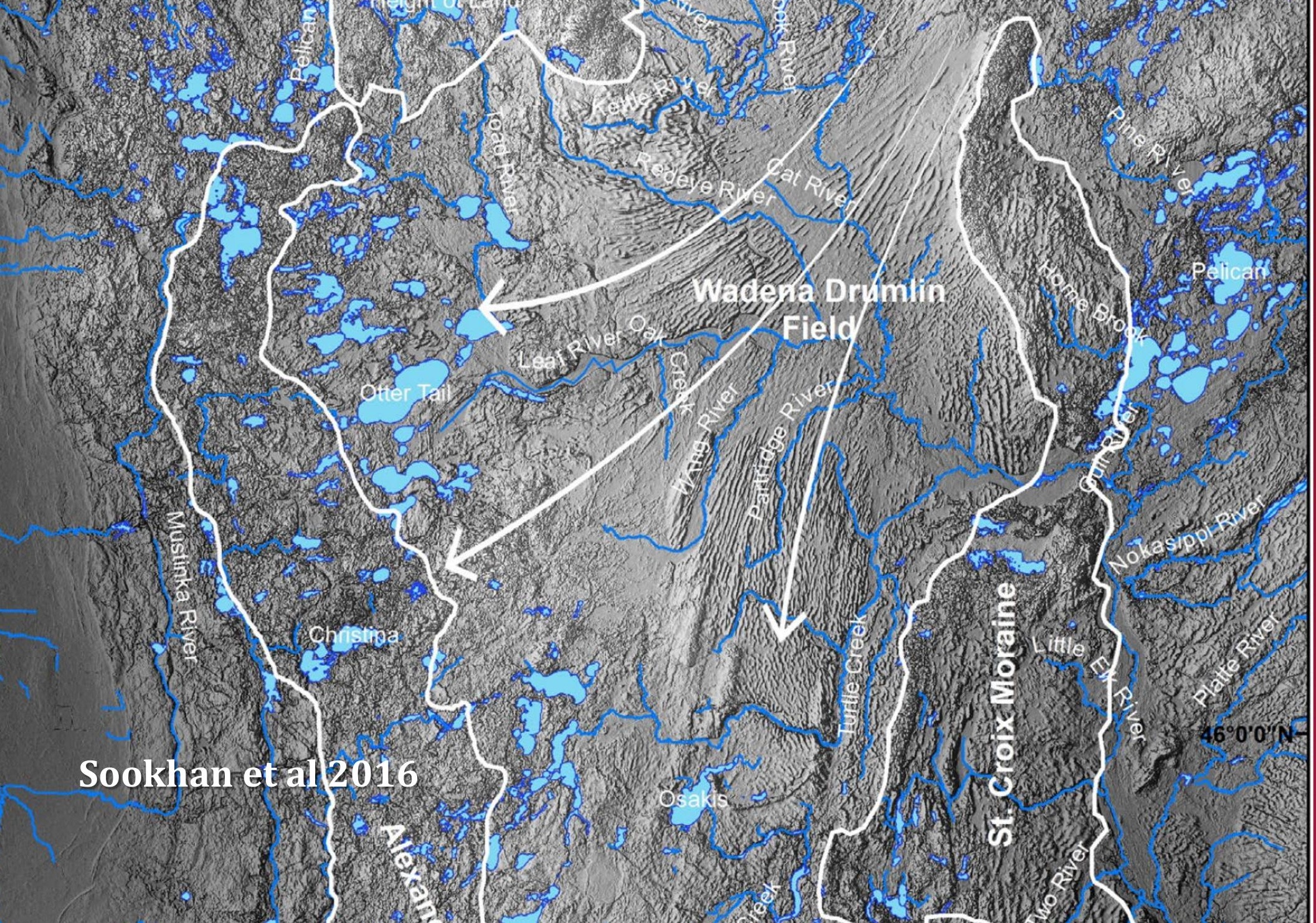




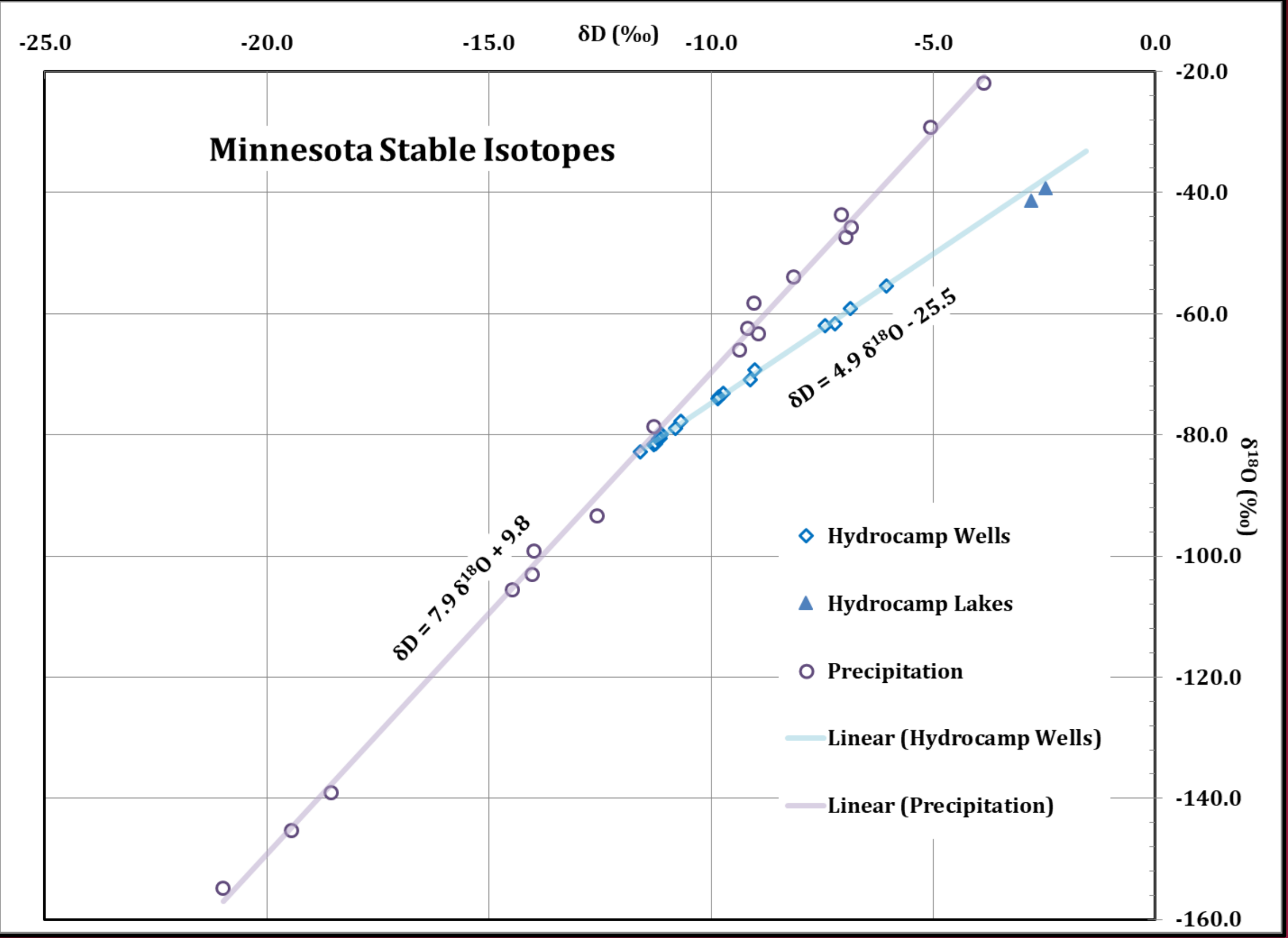




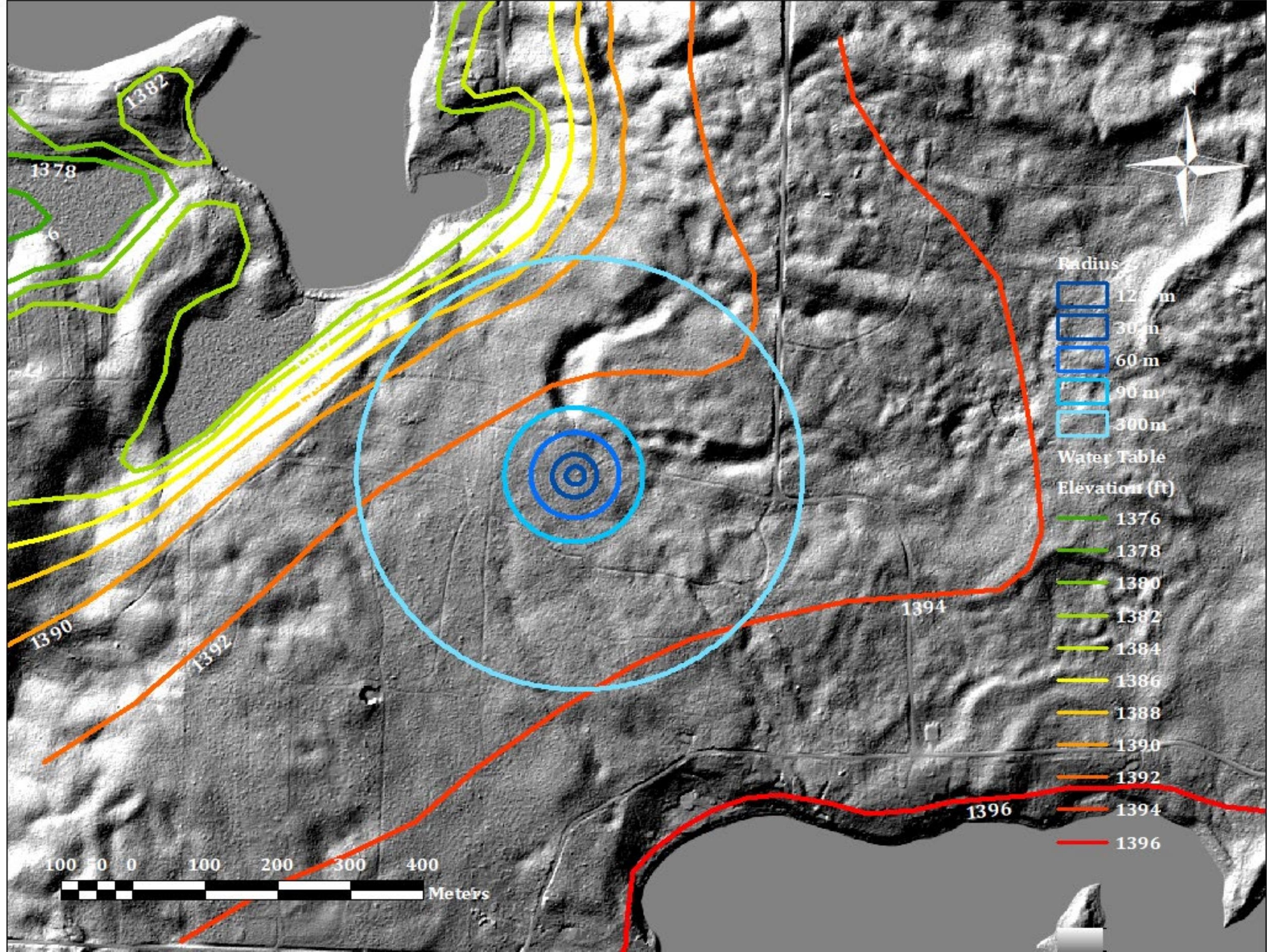




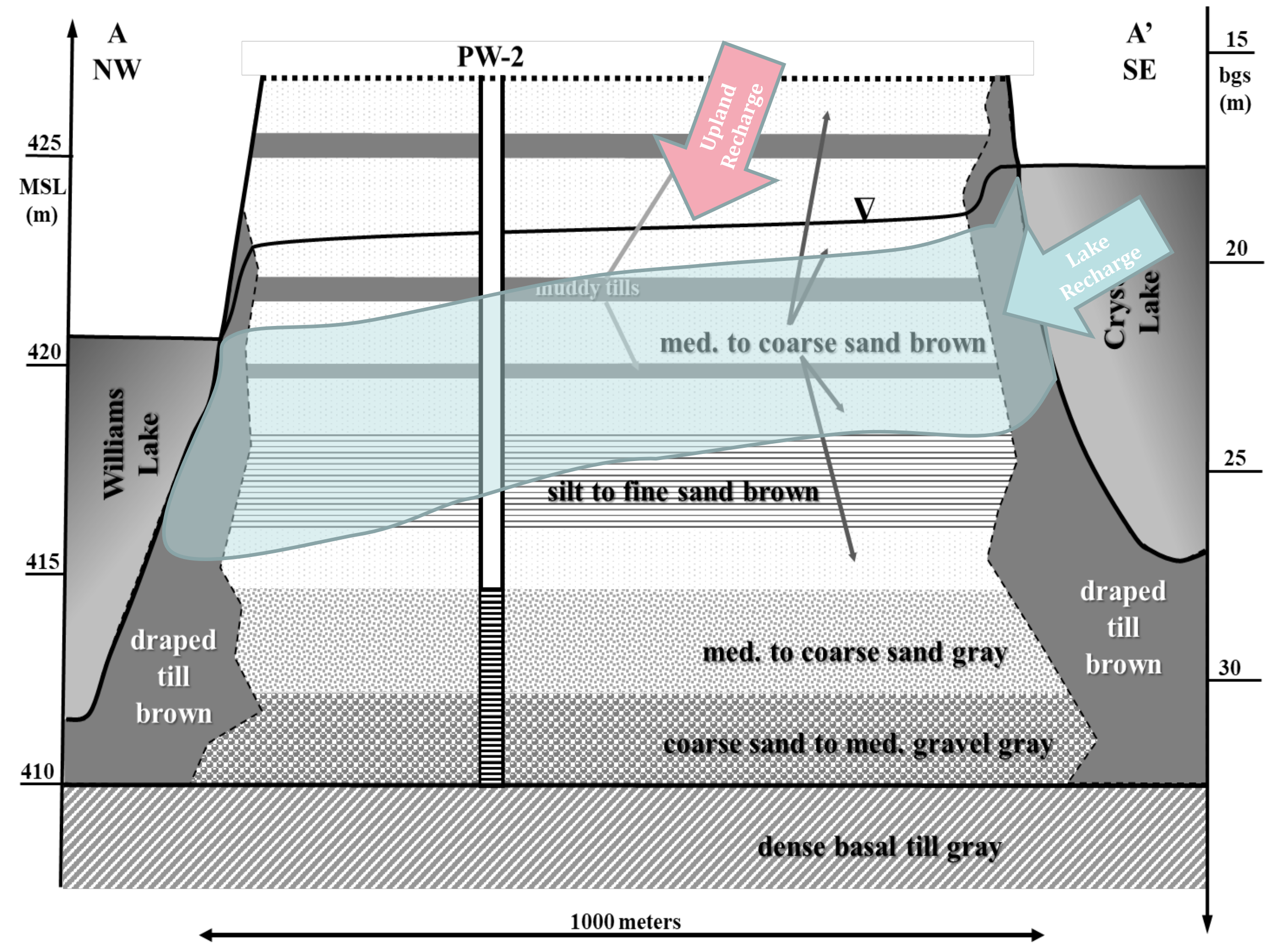




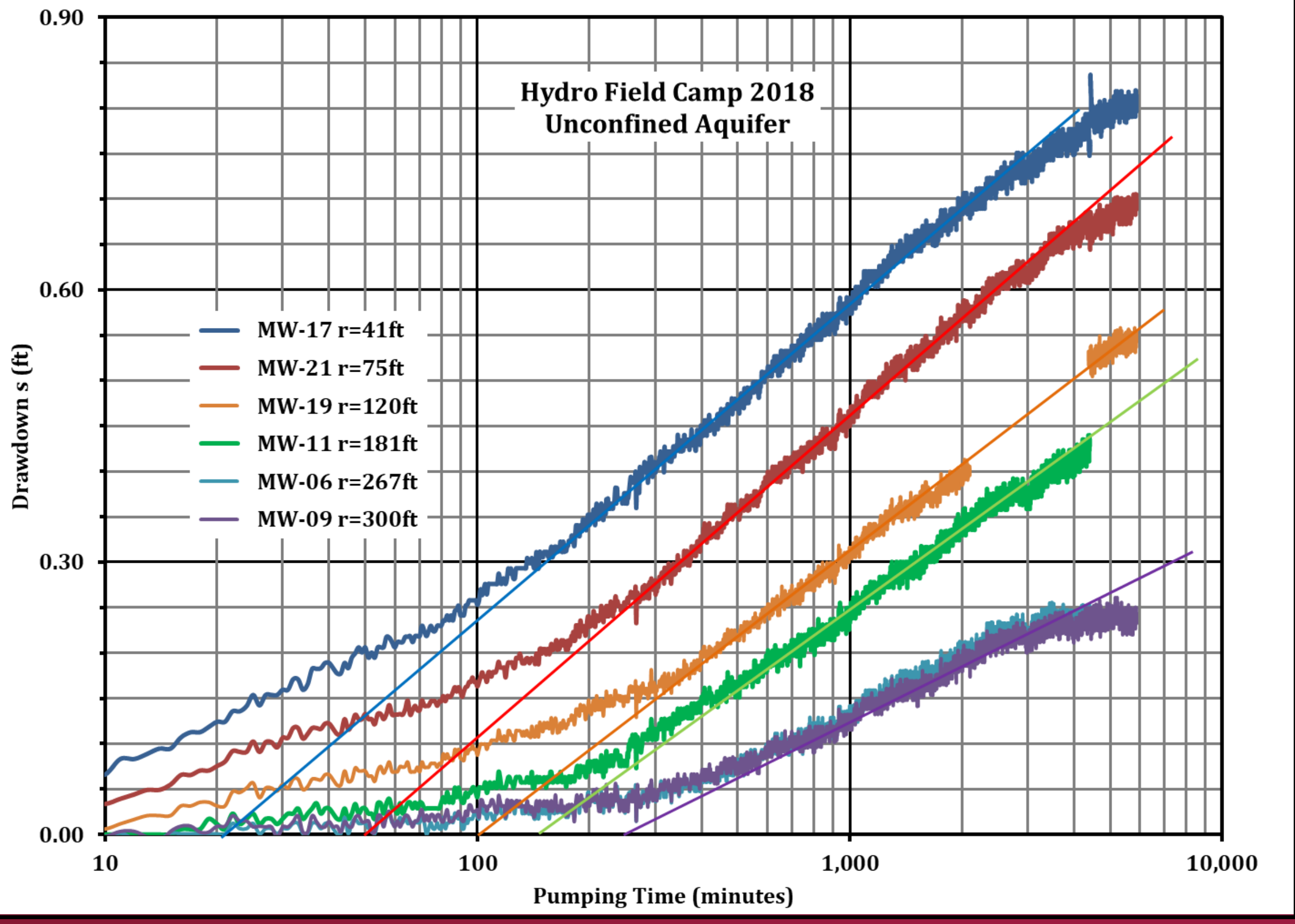




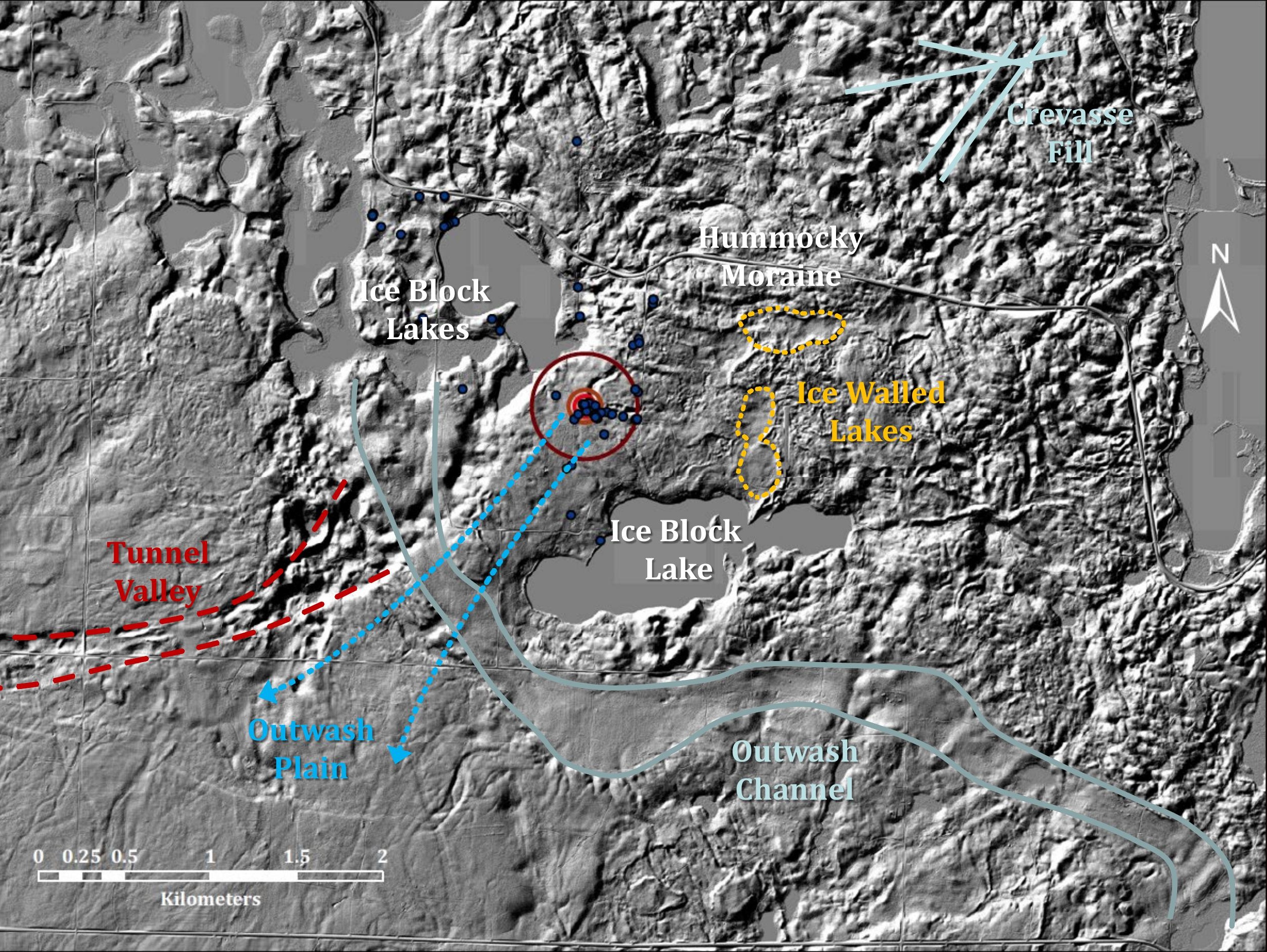




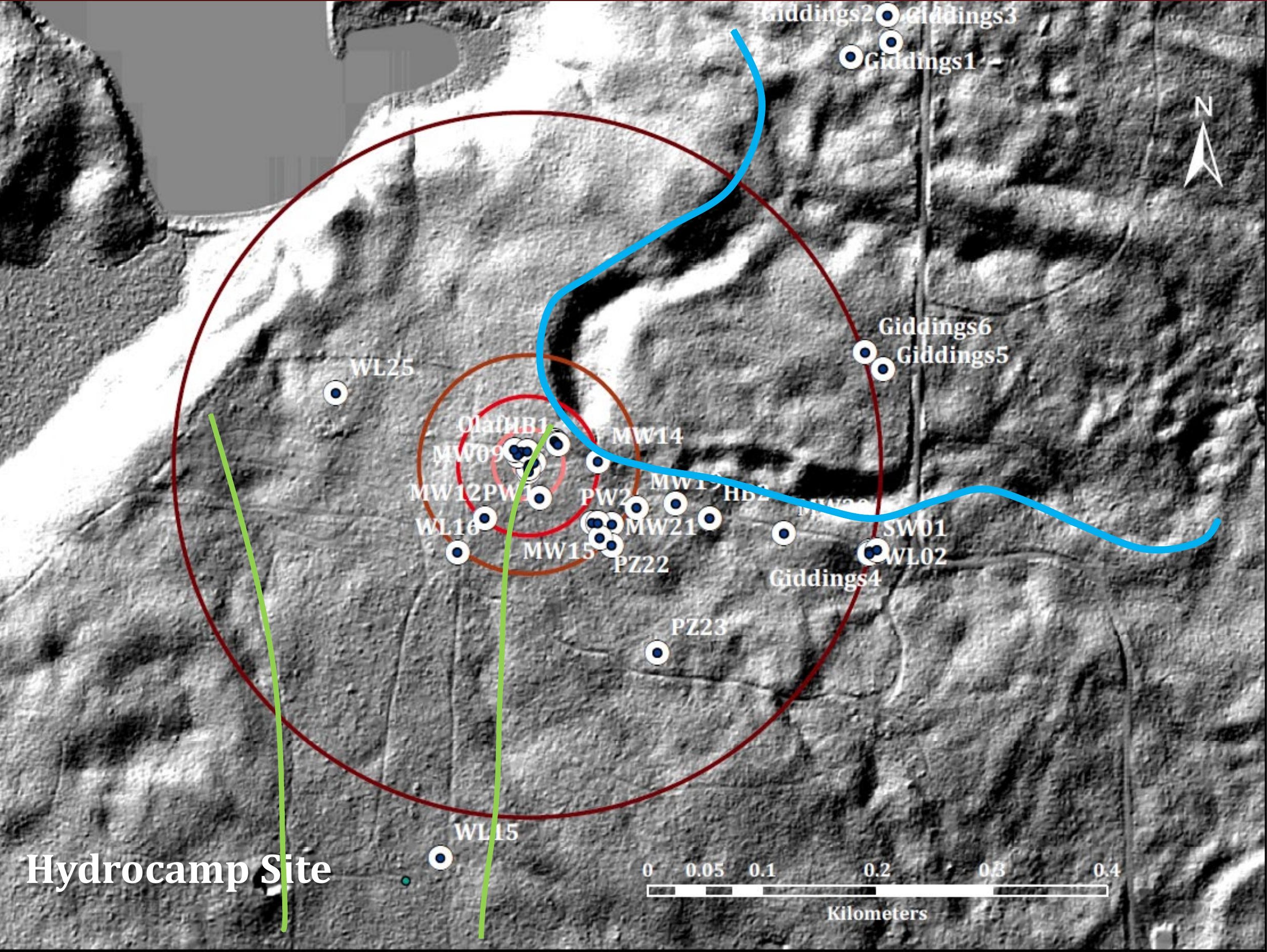




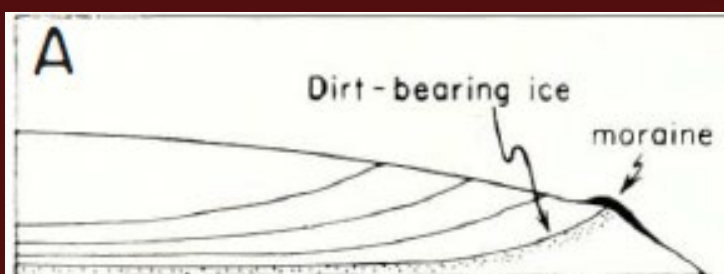

\section{Hooke 1970}

I. ICE CAP BEFORE RETREAT

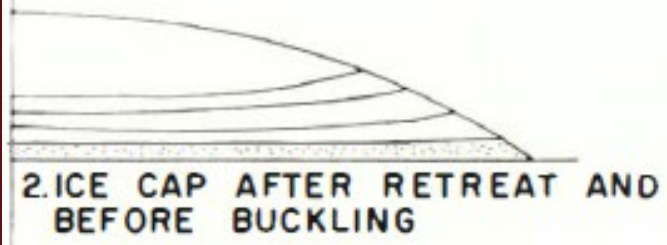

\section{BEFORE BUCKLING}

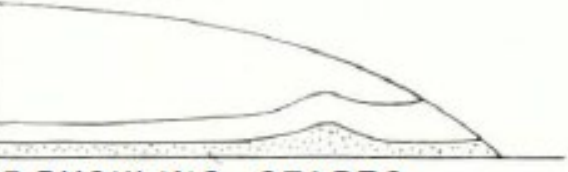

3. BUCKLING STARTS

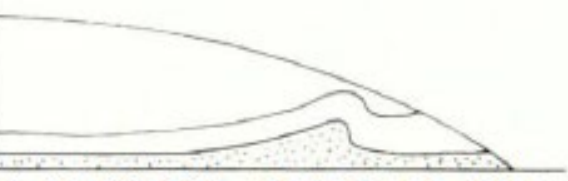

4. ADVANCED STAGE OF BUCKLING

Dirty ice still present in wedge

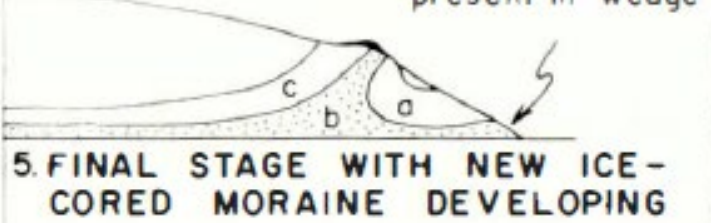
o. Essentially stognant ice
c. Slowly deforming ice
c Active glocial ice

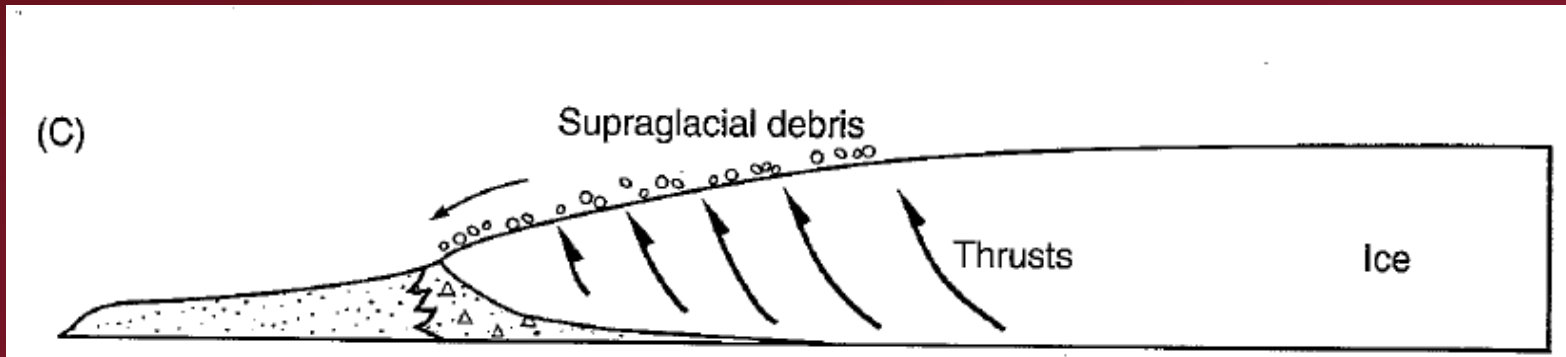

(B)

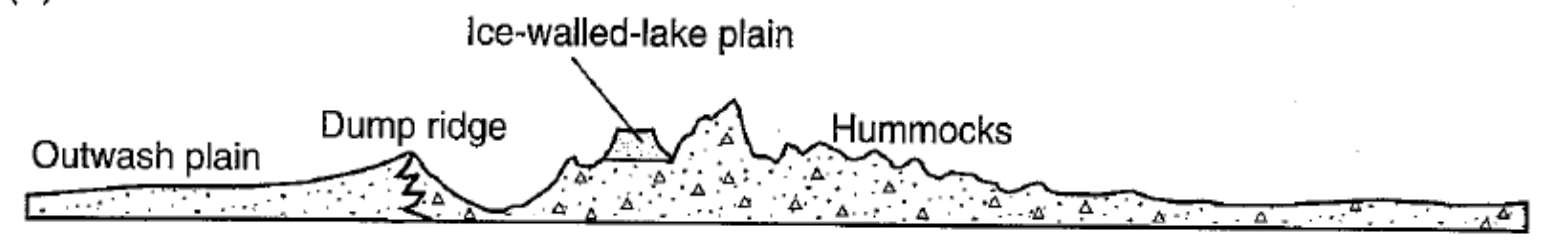




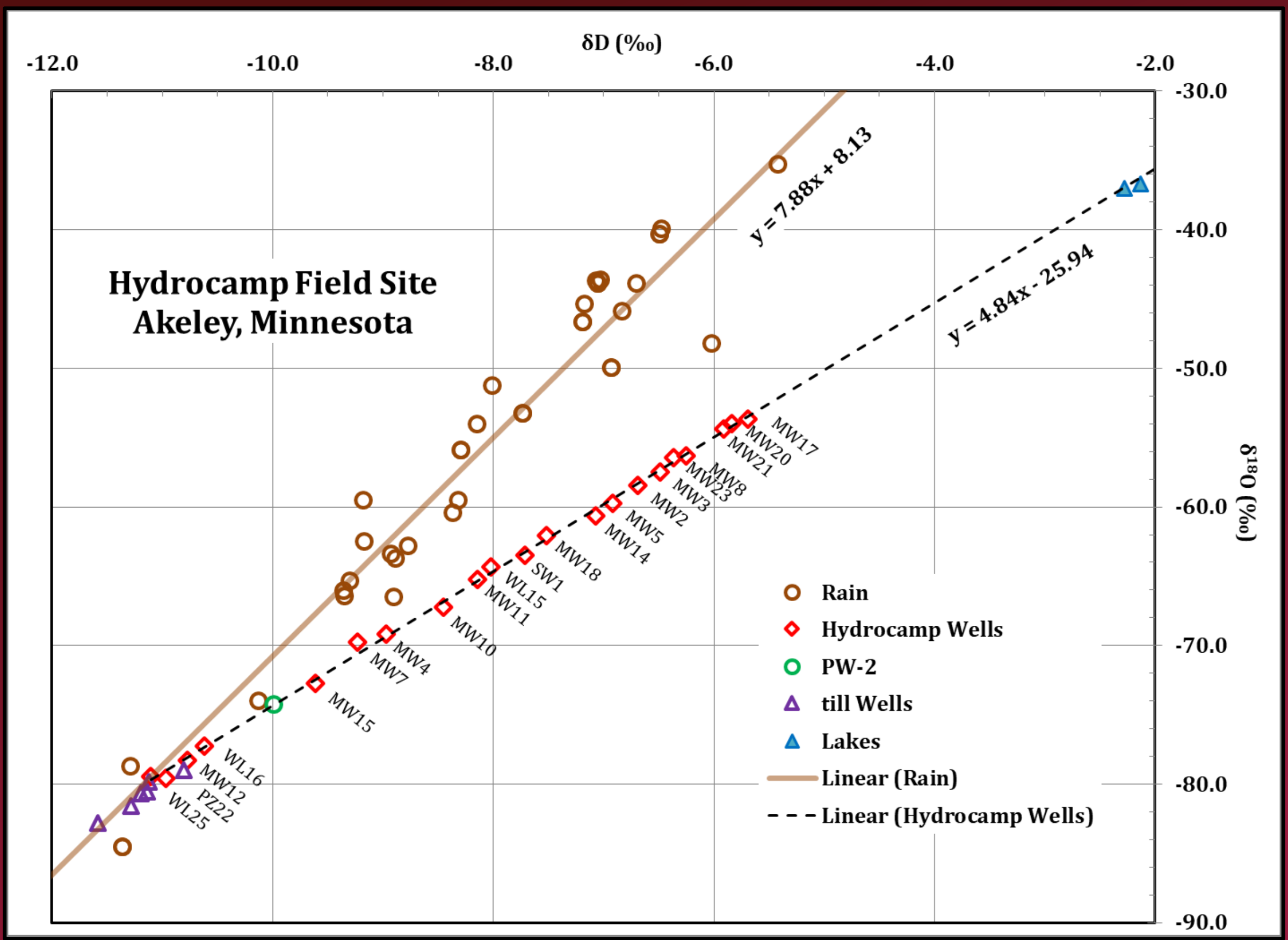




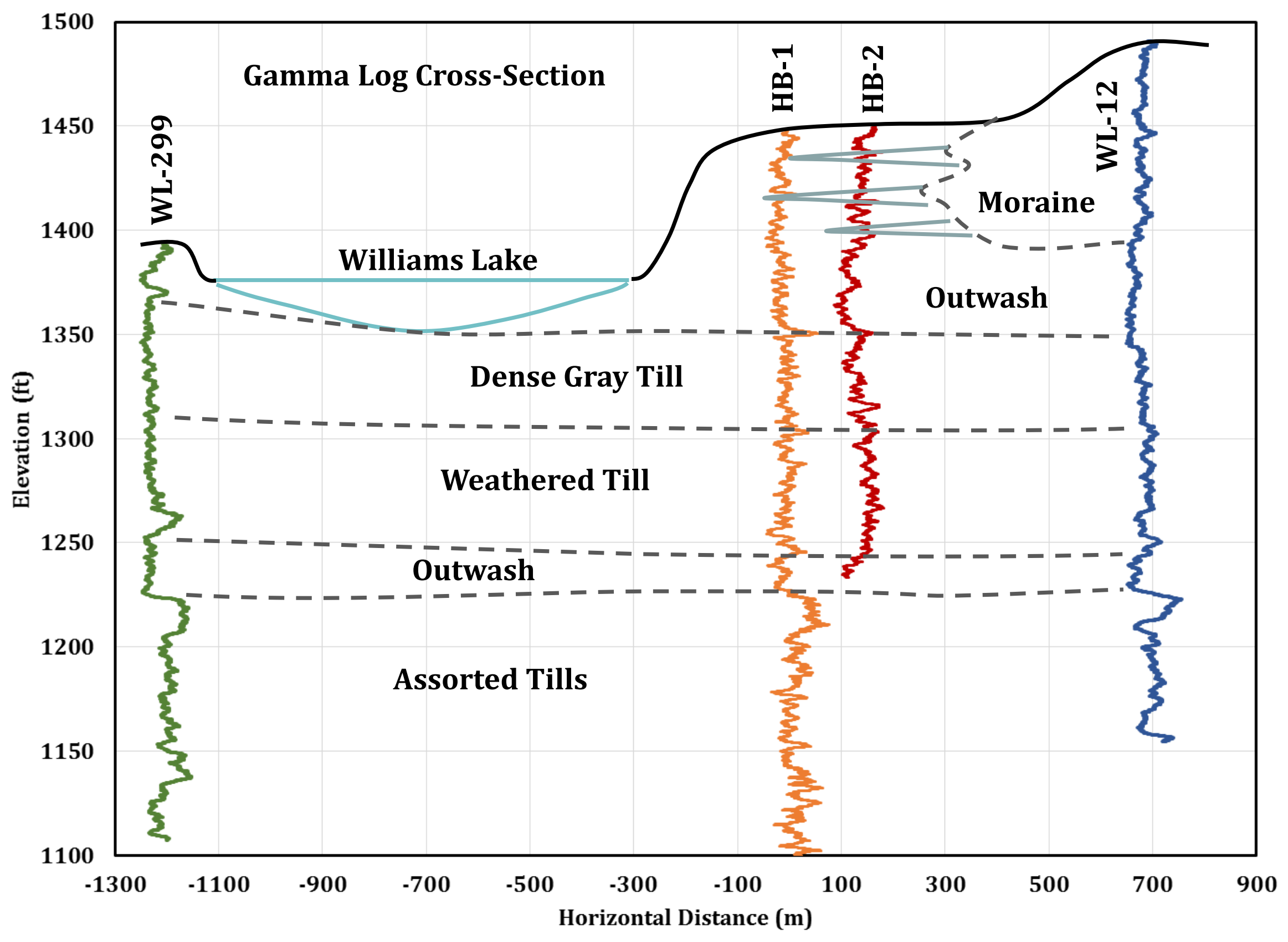




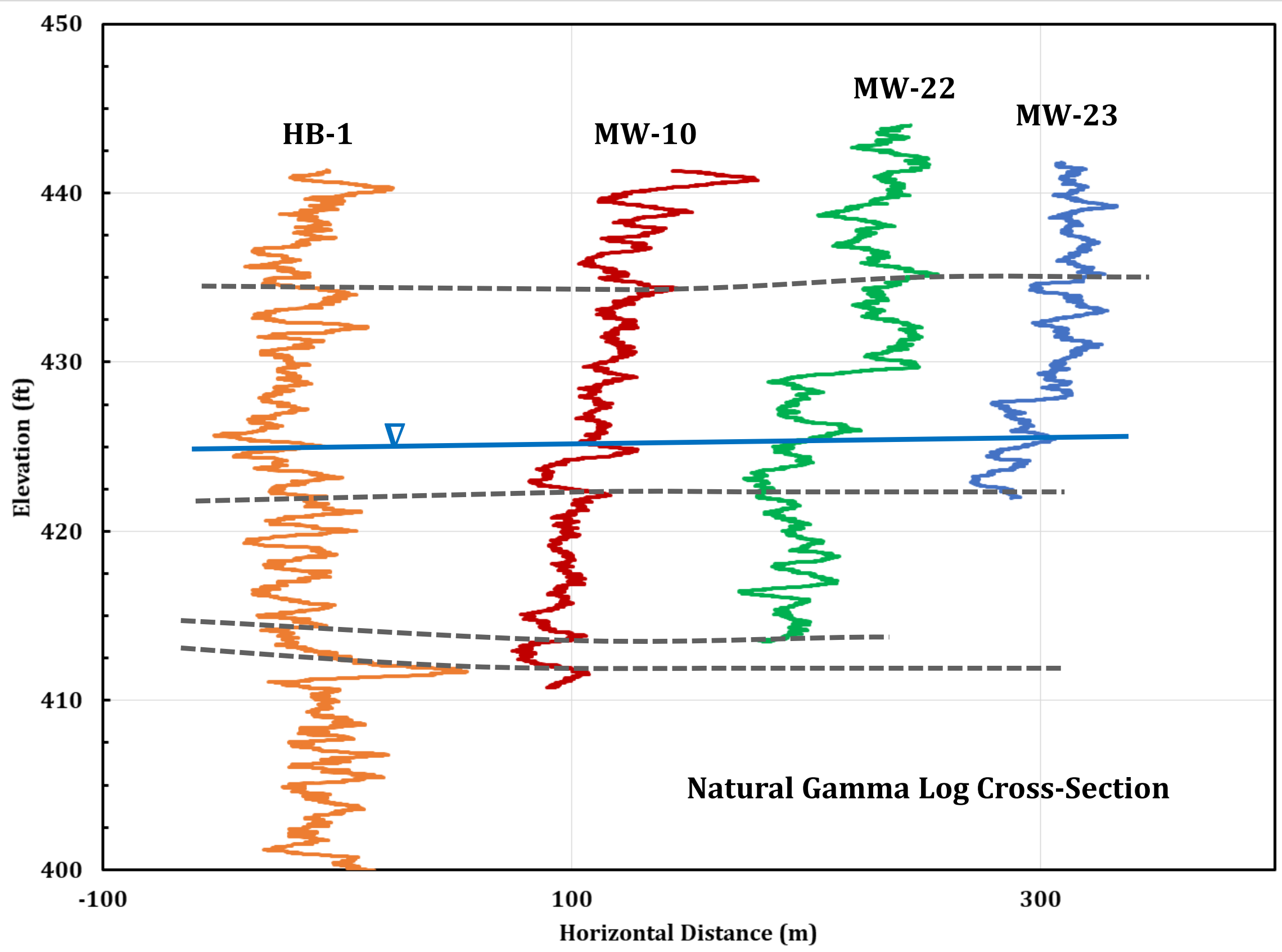




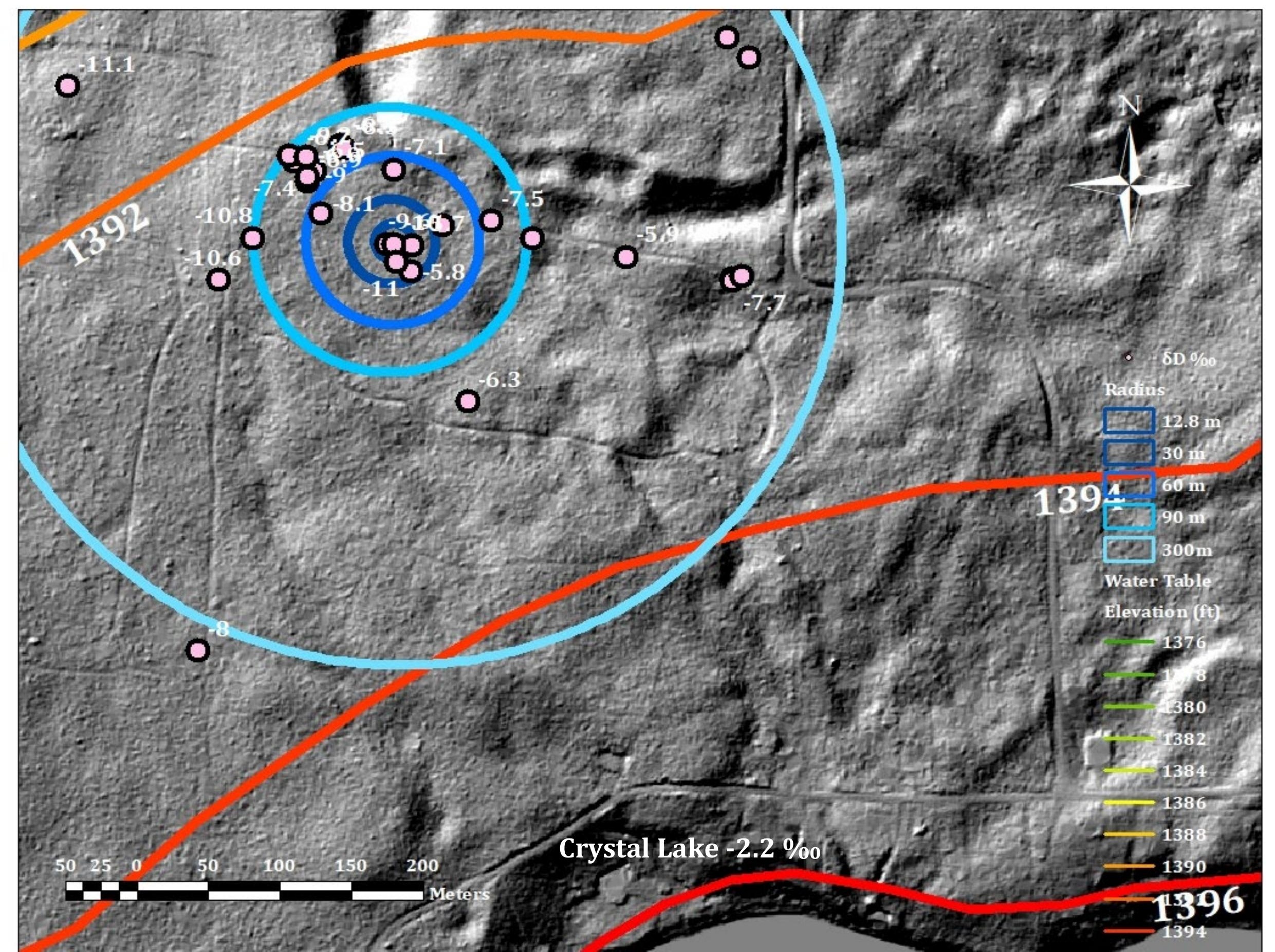




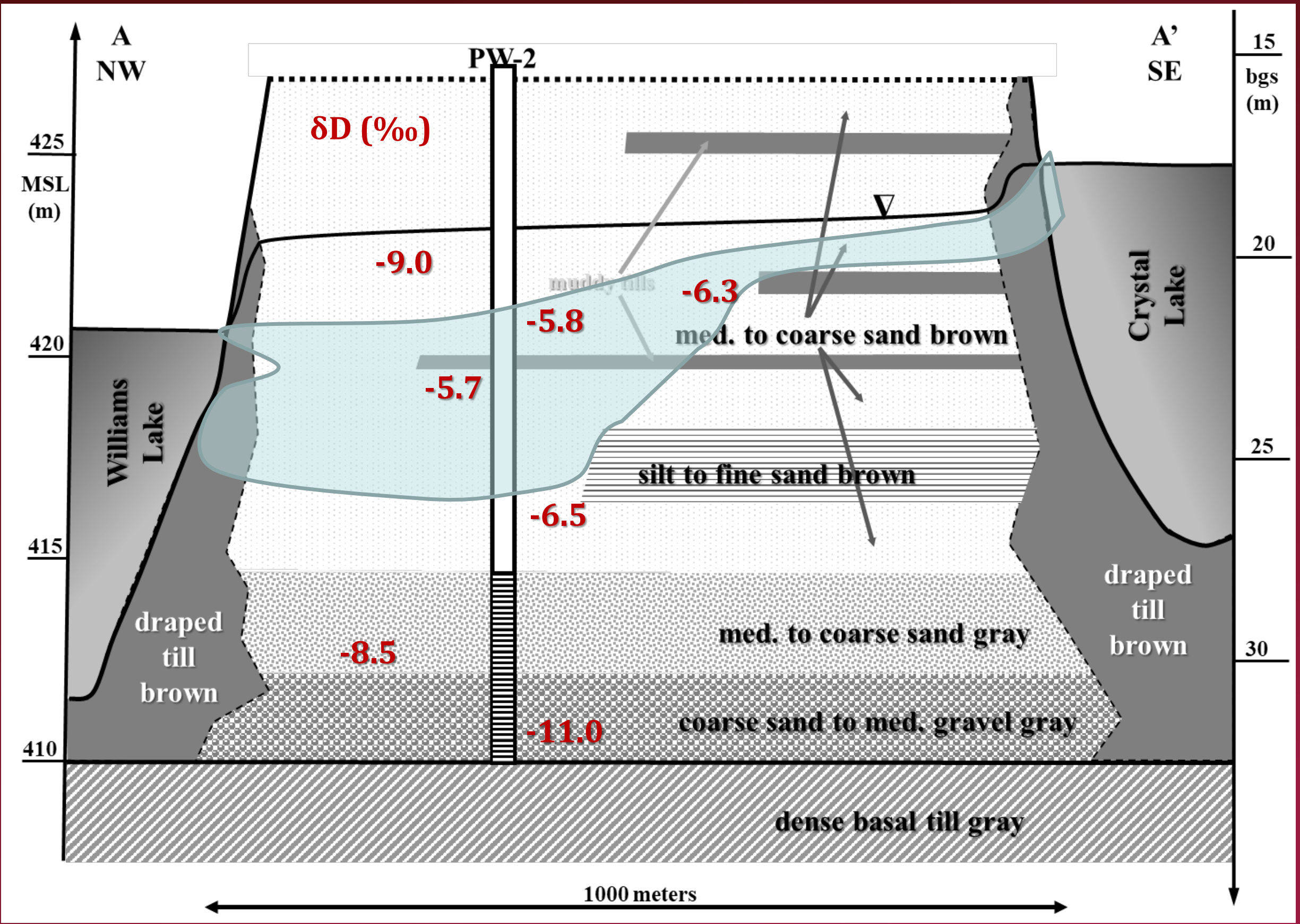




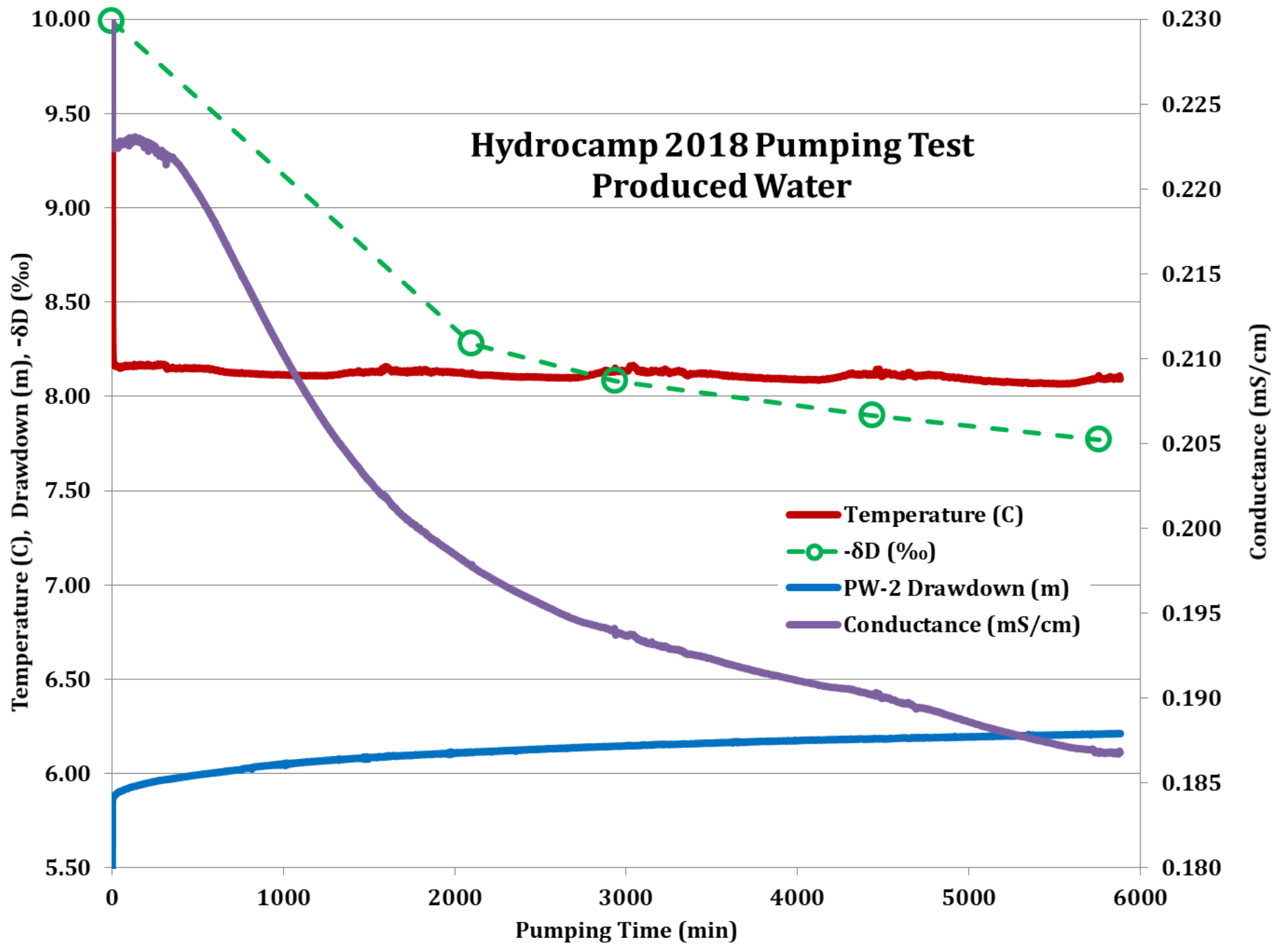




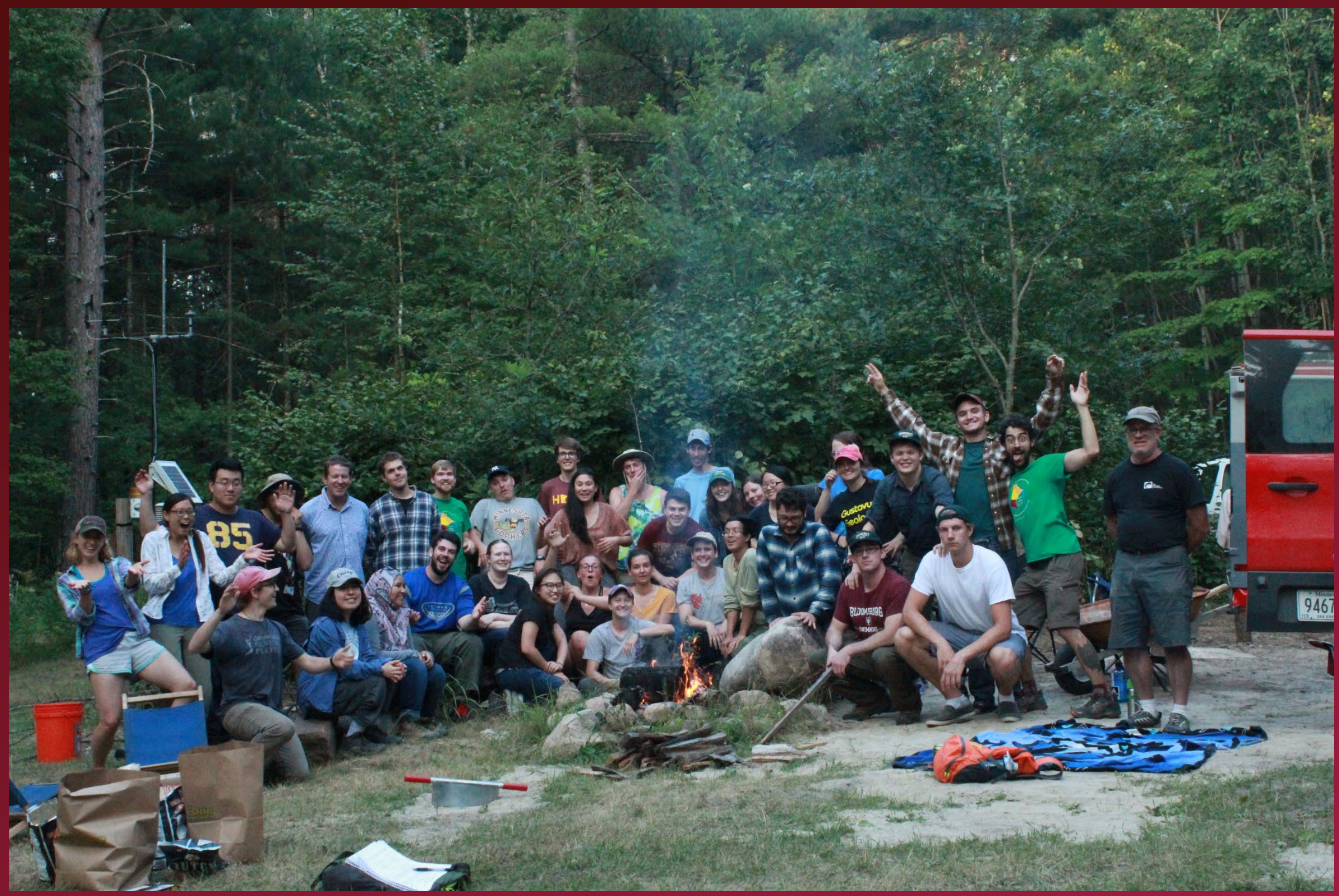

Hydrocamp Site 2017 